\title{
Are we producing general surgeons who are ready for community or rural practice?
}

\author{
Jake Hiebert, MD \\ Leo Chen, MSc \\ Hamish Hwang, MD
}

Accepted Sept. 12, 2020

\author{
Correspondence to: \\ J. Hiebert \\ General Surgery Residency Program \\ University of British Columbia \\ 2775 Laurel St \\ Vancouver BC V5Z $1 \mathrm{M} 9$ \\ jake.hiebert@alumni.ubc.ca
}

Cite as: Can J Surg 2021 September 1; 64(5). doi: $10.1503 /$ cjs.014119

\section{SUMmaRY}

General surgery remains a broad and unclearly defined specialty in small and medium-sized communities, where general surgeons perform more subspecialty and non-core procedures than their urban counterparts. It is unclear what specific procedures are being performed or whether today's residents are being trained to meet community needs. We surveyed the members of the British Columbia (BC) Surgical Society and found that only 3\% of BC's surgeons believe today's graduates are "definitely prepared" for a broad-based community practice. We also identified several non-core procedures performed more frequently by general surgeons in small and medium-sized communities. General surgery residency is narrowing its focus despite the fact that community general surgeons are maintaining a broad-based practice. To meet the needs of smaller communities, residency programs need to address the discrepancies that exist between the emphasis within the current training structure and the practice of our community surgeons.

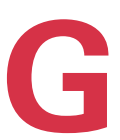
eneral surgery has changed drastically over the last several decades. There has been a gradual erosion of procedures as new specialties have emerged; a recent example is vascular surgery. While the role of a general surgeon is more clearly defined in large tertiary centres, in a rural or community setting it remains incredibly broad and variable. In 2005, a Canadian Association of General Surgeons (CAGS) survey found that general surgeons in smaller communities were performing more subspecialty and other-specialty (non-core) procedures than their urban counterparts. ${ }^{1}$ In communities with fewer than 50000 residents, the survey showed that surgeons were performing obstetrics/gynecology, plastics, orthopedics and urology procedures. The Royal College of Physicians and Surgeons of Canada's definition of general surgery is sympathetic to this and includes a caveat that states "general surgeons may provide care for patients with a broad range of surgical conditions, depending on the specific practice environment." 2

Because much of resident training takes place in large centres, are we certain that we are training residents to be competent as well-rounded community surgeons? ${ }^{3}$ We sought to determine whether general surgeons in British Columbia believe residents are graduating ready for a community/rural practice, what procedures they are performing that would typically be performed by other specialists at large centres, and whether graduating residents should be comfortable performing these procedures.

\section{SURVEY}

We designed an online survey using the Qualtrics survey tool. The survey was distributed through the BC Surgical Society members email list. Most general surgeons in British Columbia are members of this society. A reminder email to complete the survey was sent out 2 months later. The 
survey captured demographics, residency graduation year, fellowship training, and population size served. Surgeons were asked if today's general surgery residents are graduating prepared for broad-based community practice. We created a list of "non-core" procedures that we felt general surgeons in rural settings could reasonably perform that traditionally belong to other specialties: plastic and orthopedic surgery (Table 1), urology (Table 2), obstetrics and gynecology (Table 3), vascular surgery (Table 4), otolaryngology (Table 5), neurosurgery (Table 6) and endoscopy (Table 7). For every procedure, respondents indicated whether they have performed that procedure in their practice, the frequency performed on an annual basis, the training required to perform the procedure, and whether graduating residents should be comfortable with the procedure.

\begin{tabular}{|c|c|c|c|}
\hline Procedure & Small (\%) & Mid (\%) & Large (\%) \\
\hline Carpal tunnel release & 36.4 & 35.3 & 18.2 \\
\hline Trigger finger release & 18.2 & 18.2 & 14.7 \\
\hline Fasciectomy & 9.1 & 11.8 & 6.1 \\
\hline Ulnar transposition & 0 & 8.8 & 5.1 \\
\hline Tendon repairs* & 45.5 & 14.7 & 12.1 \\
\hline Facial soft tissue excision & 63.6 & 52.9 & 21.2 \\
\hline Ganglion excision & 54.5 & 55.9 & 33.3 \\
\hline Skin grafts* & 63.6 & 41.2 & 24.2 \\
\hline Skin flaps & 54.5 & 55.9 & 54.5 \\
\hline
\end{tabular}

Table 2. Urology procedures included in survey, by percentage of surgeons performing in small, mid-sized, and large centres

\begin{tabular}{lccc|} 
Procedure & Small (\%) & Mid (\%) & Large \%) \\
\hline Vasectomy & 36.4 & 29.4 & 15.2 \\
\hline Circumcision & 36.4 & 29.4 & 15.2 \\
\hline Orchiectomy & 54.5 & 35.3 & 30.3 \\
\hline Hydrocelectomy & 63.6 & 55.9 & 27.3 \\
\hline $\begin{array}{l}\text { Orchiopexy for } \\
\text { testicular torsion }\end{array}$ & 45.5 & 17.7 & 16.6 \\
\hline Cystoscopy & 9.1 & 2.9 & 2.5 \\
\hline
\end{tabular}

Table 3. Obstetrics and gynecology procedures included in survey, by percentage of surgeons performing in small, mid-sized, and large centres

\begin{tabular}{|lccc|}
\hline Procedure & Small (\%) & Mid (\%) & Large (\%) \\
\hline Cesarean section & 45.5 & 14.7 & 9.1 \\
\hline Tubal ligation & 36.4 & 8.8 & 9.1 \\
\hline Oophorectomy & 54.4 & 50.0 & 57.6 \\
\hline Hysterectomy & 36.4 & 14.7 & 27.3 \\
\hline Dilation and curettage & 18.2 & 2.9 & 3.0 \\
\hline Salpingectomy & 45.5 & 26.5 & 30.3 \\
\hline Ovarian cystectomy & 54.5 & 14.7 & 21.2 \\
\hline
\end{tabular}

Table 4. Vascular surgery procedures included in survey, by percentage of surgeons performing in small, mid-sized, and large centres

\begin{tabular}{|lccc|}
\hline Procedure & Small (\%) & Mid (\%) & Large (\%) \\
\hline Vein stripping & 54.5 & 14.7 & 21.2 \\
\hline Vascular access & 100 & 76.5 & 69.2 \\
\hline Amputation & 63.6 & 32.4 & 21.2 \\
\hline
\end{tabular}

Table 5. Otolaryngology procedures included in survey, by percentage of surgeons performing in small, mid-sized, and large centres

\begin{tabular}{|lccc|}
\hline Procedure & Small (\%) & Mid (\%) & Large (\%) \\
\hline Thyroidectomy & 54.5 & 70.6 & 51.5 \\
\hline Parathyroidectomy & 9.1 & 32.4 & 39.4 \\
\hline Parotidectomy & 36.4 & 35.3 & 27.3 \\
\hline $\begin{array}{l}\text { Submandibular gland } \\
\text { excision }\end{array}$ & 45.5 & 20.6 & 30.3 \\
\hline Tonsillectomy & 9.1 & 5.9 & 3.0 \\
\hline $\begin{array}{l}\text { Branchial cleft/thyroglossal } \\
\text { duct excision }\end{array}$ & 36.4 & 35.3 & 21.2 \\
\hline Tracheostomy & 72.7 & 73.5 & 72.7 \\
\hline
\end{tabular}

Table 6. Neurosurgery procedures included in survey, and percentage of surgeons performing in small, mid-sized, and large centres

\begin{tabular}{|lccc|}
\hline Procedure & Small $(\%)$ & Mid $(\%)$ & Large $(\%)$ \\
\hline Burr hole & 18.2 & 17.6 & 12.1 \\
\hline
\end{tabular}

Table 7. Advanced endoscopic procedures included in survey, by percentage of surgeons performing in small, mid-sized, and large centres

\begin{tabular}{lccc} 
Procedure & Small (\%) & Mid (\%) & Large (\%) \\
\hline ERCP & 18.2 & 8.8 & 3.0 \\
\hline Stenting & 27.3 & 17.1 & 17.9 \\
\hline Variceal banding & 81.8 & 64.7 & 21.2 \\
\hline Esophageal dilations & 100 & 82.4 & 69.2 \\
\hline EMR & 54.5 & 50.0 & 36.4 \\
\hline Piecemeal polyp & 90.9 & 85.3 & 72.7 \\
\hline PEG tube placement & 100 & 94.1 & 91.0 \\
\hline EUS & 0 & 0 & 2.6 \\
\hline $\begin{array}{l}\text { EMR = endoscopic mucosal resection; ERCP = endoscopic retrograde cholangiopancrea- } \\
\text { tography; EUS = endoscopic ultrasonography; PEG = percutaneous endoscopic } \\
\text { gastrostomy. }\end{array}$ &
\end{tabular}

Responses were categorized according to the population size served by the respondent: small $(<50000)$, midsized (50000-200000) and large (> 200000$)$. The small and mid-sized communities were compared with the large communities for each procedure using logistic regression analysis.

Of 170 members of the BC Surgical Society, 98 responded (57.6\%). We excluded 20 surveys (5 surgeons no longer practising, 1 did not consent, and 14 surveys were incomplete), leaving 78 (45.9\%) surveys for analysis: $11(14.1 \%)$ from small, 34 (43.6\%) from mid-sized, and $33(42.3 \%)$ from large communities. The survey took an 
average of 12.9 minutes to complete. The mean year of residency graduation was 2003 (range 1978-2015). Fellowship training had been completed by $54.5 \%$ of surgeons in small, $35.3 \%$ in mid-sized, and $60.6 \%$ in large centres, with significantly fewer fellowships in mid-sized centres $(p=0.04)$. When asked if today's general surgery residents are graduating ready for a broad-based community practice, $3 \%$ of surgeons responded definitely yes, $48 \%$ probably, $42 \%$ probably not, and $7 \%$ definitely not, with no significant difference between answers from surgeons serving different population sizes.

Procedures performed significantly more often in small than in large communities were tendon repair (OR $6.04, p=0.026)$, facial soft tissue surgery $(6.50, p=0.014)$, skin grafting $(5.47, p=0.023)$, circumcision (OR 8.86, $p=$ 0.023 ), hydrocelectomy (OR 4.67, $p=0.037$ ), tubal ligation (OR 5.71, $p=0.046)$, Cesarean section (OR 8.33, $p=$ 0.013 ), ovarian cystectomy (OR 4.46, $p=0.043$ ), varicose vein surgery (OR 4.46, $p=0.043)$, amputation (OR 6.50,

\begin{tabular}{|c|c|c|c|c|c|}
\hline Procedure & $\begin{array}{l}\text { Population } \\
\text { size }\end{array}$ & $\%$ performed & OR ( $p$ value) & $\begin{array}{l}\text { Annual } \\
\text { average }\end{array}$ & $\begin{array}{l}\text { Definitely/ } \\
\text { probably yes }\end{array}$ \\
\hline \multirow[t]{2}{*}{ Tendon repair } & $<50 k$ & $45.5 \%$ & $6.04(0.026)$ & $\begin{array}{l}2.40 \text { Ext } \\
\text { 3.50 Flex }\end{array}$ & $40 \%$ \\
\hline & $50-200 K$ & $14.7 \%$ & $1.25(0.757)$ & $\begin{array}{l}\text { 4.67 Ext } \\
\text { 2.00 Flex }\end{array}$ & $20 \%$ \\
\hline Face soft tissue & $\begin{array}{c}<50 k \\
50-200 K\end{array}$ & $\begin{array}{l}63.6 \% \\
52.9 \%\end{array}$ & $\begin{array}{l}6.50(0.014) \\
4.18(0.009)\end{array}$ & $\begin{array}{c}26.14 \\
8.88\end{array}$ & $\begin{array}{l}85.7 \% \\
89.9 \%\end{array}$ \\
\hline \multirow[t]{2}{*}{ Skin graft } & $<50 k$ & $63.6 \%$ & $5.47(0.023)$ & $\begin{array}{l}5.86 \text { STSG } \\
4.25 \text { FTSG }\end{array}$ & $100 \%$ \\
\hline & $50-200 K$ & $41.2 \%$ & $2.19(0.144)$ & $\begin{array}{l}\text { 4.40 STSG } \\
2.33 \text { FTSG }\end{array}$ & $92.9 \%$ \\
\hline Circumcision & $\begin{array}{c}<50 \mathrm{~K} \\
50-200 \mathrm{~K}\end{array}$ & $\begin{array}{l}36.4 \% \\
11.8 \%\end{array}$ & $\begin{array}{l}8.86(0.023) \\
2.07(0.421)\end{array}$ & $\begin{array}{l}4.50 \\
6.67\end{array}$ & $\begin{array}{c}75 \% \\
100 \%\end{array}$ \\
\hline Hydrocelecomy & $\begin{array}{c}<50 \mathrm{~K} \\
50-200 \mathrm{~K}\end{array}$ & $\begin{array}{l}63.6 \% \\
55.9 \%\end{array}$ & $\begin{array}{c}4.67(0.037) \\
3.38(0.02)\end{array}$ & $\begin{array}{l}3.33 \\
4.63\end{array}$ & $\begin{array}{l}85.7 \% \\
89.5 \%\end{array}$ \\
\hline Cesarian section & $\begin{array}{c}<50 k \\
50-200 K\end{array}$ & $\begin{array}{l}45.5 \% \\
14.7 \%\end{array}$ & $\begin{array}{l}8.33(0.013) \\
1.72(0.482)\end{array}$ & $\begin{array}{c}9.50 \\
5\end{array}$ & $\begin{array}{l}60 \% \\
80 \%\end{array}$ \\
\hline Tubal ligation & $\begin{array}{c}<50 \mathrm{~K} \\
50-200 \mathrm{~K}\end{array}$ & $\begin{array}{c}36.6 \% \\
8.8 \%\end{array}$ & $\begin{array}{l}5.71(0.046) \\
0.97(0.969)\end{array}$ & $\begin{array}{l}2 \\
0\end{array}$ & $\begin{array}{c}75 \% \\
66.7 \%\end{array}$ \\
\hline $\begin{array}{l}\text { Ovarian } \\
\text { cystectomy }\end{array}$ & $\begin{array}{c}<50 \mathrm{k} \\
50-200 \mathrm{~K}\end{array}$ & $\begin{array}{l}54.6 \% \\
14.7 \%\end{array}$ & $\begin{array}{c}4.46(0.043) \\
0.224(0.043)\end{array}$ & $\begin{array}{c}2.67 \\
2\end{array}$ & $\begin{array}{l}83.3 \% \\
100 \%\end{array}$ \\
\hline Varicose vein & $\begin{array}{c}<50 \mathrm{~K} \\
50-200 \mathrm{~K}\end{array}$ & $\begin{array}{l}54.6 \% \\
35.3 \%\end{array}$ & $\begin{array}{l}4.46(0.043) \\
2.03(0.205)\end{array}$ & $\begin{array}{c}10.25 \\
16.5\end{array}$ & $\begin{array}{l}83.3 \% \\
91.7 \%\end{array}$ \\
\hline Vascular access & $\begin{array}{c}<50 \mathrm{k} \\
50-200 \mathrm{~K}\end{array}$ & $\begin{array}{l}100 \% \\
76.5 \%\end{array}$ & $\begin{array}{c}\text { NA } \\
3.05(0.036)\end{array}$ & $\begin{array}{l}17.3 \\
14.6\end{array}$ & $\begin{array}{l}100 \% \\
100 \%\end{array}$ \\
\hline Amputation & $\begin{array}{c}<50 \mathrm{~K} \\
50-200 \mathrm{~K}\end{array}$ & $\begin{array}{l}63.6 \% \\
32.4 \%\end{array}$ & $\begin{array}{l}6.50(0.014) \\
1.78(0.306)\end{array}$ & $\begin{array}{l}3,83 \\
6.17\end{array}$ & $\begin{array}{l}100 \% \\
63.6 \%\end{array}$ \\
\hline Banding varices & $\begin{array}{c}<50 \mathrm{~K} \\
50-200 \mathrm{~K}\end{array}$ & $\begin{array}{l}81.8 \% \\
64.7 \%\end{array}$ & $\begin{array}{c}16.71(0.002) \\
6.81(0.001)\end{array}$ & $\begin{array}{l}9.33 \\
9.59\end{array}$ & $\begin{array}{l}77.8 \% \\
91.9 \%\end{array}$ \\
\hline Eo dilations & $\begin{array}{c}<50 \mathrm{k} \\
50-200 \mathrm{~K}\end{array}$ & $\begin{array}{l}100 \% \\
82.4 \%\end{array}$ & $\begin{array}{c}\text { NA } \\
5.60(0.002)\end{array}$ & $\begin{array}{l}11.3 \\
16.4\end{array}$ & $\begin{array}{l}100 \% \\
96.4 \%\end{array}$ \\
\hline Peg tube & $\begin{array}{c}<50 \mathrm{k} \\
50-200 \mathrm{~K}\end{array}$ & $\begin{array}{l}100 \% \\
94.1 \%\end{array}$ & $\begin{array}{c}N A \\
3.56(0.139)\end{array}$ & $\begin{array}{l}7.10 \\
9.94\end{array}$ & $\begin{array}{l}100 \% \\
100 \%\end{array}$ \\
\hline $\begin{array}{l}\text { Ext = extensor tend } \\
\text { thickness skin graft. } \\
\text { medium-sized comr } \\
\text { graduating resident }\end{array}$ & $\begin{array}{l}\text { hities compare } \\
\text { hould be compe }\end{array}$ & $\begin{array}{l}\text { with large, and the } \\
\text { ent in the procedu }\end{array}$ & $\begin{array}{l}\text { being performed } \\
\text { pinion of surgeon }\end{array}$ & $\begin{array}{l}=\text { odds ratio } \\
\text { ficantly mor } \\
\text { of whether }\end{array}$ & $\begin{array}{l}\mathrm{G}=\text { split } \\
\text { small or } \\
\text { today's }\end{array}$ \\
\hline
\end{tabular}

$p=0.014)$ and banding of esophageal varices (OR 16.71, $p=0.002)$. For vascular access surgery, esophageal dilations and percutaneous endoscopic gastrostomy tube placement, ORs and $p$ values could not be calculated because $100 \%$ of surgeons in small communities perform these procedures.

Procedures performed significantly more often in mid-sized than in large communities were facial soft tissue surgery (OR 4.18, $p=0.009$ ), hydrocelectomy $(\mathrm{OR} 3.38, p=0.02)$, ovarian cystectomy (OR $0.224, p=$ $0.043)$, vascular access surgery (OR 3.05, $p=0.036)$, endoscopic banding of esophageal varices (OR 6.81, $p=$ 0.001 ), and esophageal dilations (OR 5.60, $p=0.002$ ). Table 8 shows the significant procedures, the percentage of surgeons performing them, the annual average of procedures performed per surgeon, and the surgeons' opinion on whether today's graduates should be competent in that procedure.

Table 9 shows how surgeons trained to perform these procedures. At least half of surgeons identified residency as the source of their procedural competence for tendon repair, skin grafting, circumcision, hydrocelectomy, tubal ligation, ovarian cystectomy, varicose vein surgery, vascular access, amputation, esophageal dilations and percutaneous endoscopic gastrostomy (PEG) tube insertion.

Procedures most commonly performed in small and medium communities were PEG tube insertion (100\% and $94.1 \%$, respectively), esophageal dilations $(100 \%$ and $82.4 \%$, respectively), banding of esophageal varices $(81.8 \%$ and $64.7 \%$, respectively) and vascular access surgery $(100 \%$ and $76.5 \%$, respectively).

For procedures listed as significant, methods for attaining competence were averaged to get a global sense of how surgeons received training. On average $6.1 \%$ had fellowships that contributed, $1.9 \%$ had a formal course or certificate, $20.2 \%$ had been mentored by a local colleague, $8.5 \%$ had been mentored by a distant colleague, $9.7 \%$ reported selfstudy, $4.38 \%$ reported "other" means for achieving competence, and $48.8 \%$ reported residency as adequate training (Figure 1).

Procedures that $75 \%$ or more of BC's surgeons felt graduating residents should probably or definitely be competent in were carpal tunnel repair $(86.4 \%)$; ganglion excision $(80.6 \%)$; 
flap surgery, including $\mathrm{V}-\mathrm{Y}$ advancement, rhomboid, and rotational procedures $(76.2 \%)$; orchiectomy $(82.1 \%)$; testicular torsion surgery $(100 \%)$; oophorectomy $(83.7 \%)$; salpingectomy $(83.3 \%)$; thyroid surgery (91.3\%); tracheostomy (98.3\%); burr hole/craniotomy (92.4\%); endoscopic mucosal resections (91.2\%); endoscopic piecemeal resections $(96.8 \%)$; and PEG tube insertion $(98.6 \%)$.

\section{Discussion}

Nearly one-third of Canada's population exists within small communities of less than 30000 people, and how best to provide surgical care for these patients remains a frequent topic of debate. ${ }^{4,5}$ While there is an argument for centralizing procedures that are both uncommon and complex (e.g., pancreaticoduodenectomy), general surgeons must serve smaller communities with broad skill sets. ${ }^{6}$ General surgeons with broad skill sets will remain a crucial component of health care delivery, therefore general surgery training ought to provide an avenue for residents to prepare for a rural practice. Many rural Canadian surgeons have reported feeling inadequately prepared for practice. ${ }^{1}$
We identified non-core procedures that are being performed more frequently in small and mid-sized compared with larger centres. Performing rotations in small and mid-sized communities provides invaluable experience for general surgery trainees; however, the annual volume for many of these procedures was found to be low. Higher-volume training experience in the identified procedures may be afforded with buy-in from our large-centre colleagues in other specialties to provide focused rotations for general surgery residents. Based on our results, areas of focus should include advanced endoscopy skills, plastic surgery, vascular surgery, obstetrics and gynecology, and urology.

While residency training was the most frequently reported means of attaining competence in the identified procedures $(48.8 \%)$, residency training is evolving. According to Canadian Resident Matching Service (CaRMS) general surgery program descriptions, if a program offers rotations in other specialties, such as plastic surgery, urology and otolaryngology, these rotations occur in postgraduate years 1 or $2.7^{7}$ It is unlikely that residents at this level of training will acquire the procedural competence required to consider this model adequate for preparing residents for community practice.

\begin{tabular}{|c|c|c|c|c|c|c|c|c|}
\hline Procedure & Population size & Fellowship & Course & Local mentor & Mentor other & Self study & Other & Residency \\
\hline \multirow[t]{2}{*}{ Tendon repair } & $<50 k$ & 0 & 0 & $33 \%$ & 0 & $16.7 \%$ & 0 & $50 \%$ \\
\hline & 50-200K & $40 \%$ & 0 & $20 \%$ & 0 & 0 & $20 \%$ & $20 \%$ \\
\hline \multirow[t]{2}{*}{ Face soft tissue } & $<50 k$ & 0 & 0 & $18.2 \%$ & $18.2 \%$ & $36.4 \%$ & 0 & $27.3 \%$ \\
\hline & 50-200K & $8.7 \%$ & $4.4 \%$ & $21.74 \%$ & $13.0 \%$ & $4.4 \%$ & $13.0 \%$ & $34.8 \%$ \\
\hline \multirow[t]{2}{*}{ Skin graft } & $<50 k$ & 0 & 0 & $10 \%$ & $10 \%$ & $20 \%$ & $10 \%$ & $50 \%$ \\
\hline & 50-200K & $9.5 \%$ & $4.8 \%$ & $28.6 \%$ & $14.3 \%$ & $4.8 \%$ & $9.5 \%$ & $28.6 \%$ \\
\hline \multirow[t]{2}{*}{ Circumcision } & $<50 k$ & 0 & 0 & $25 \%$ & 0 & 0 & 0 & $75 \%$ \\
\hline & 50-200K & 0 & 0 & $20 \%$ & $20 \%$ & 0 & 0 & $60 \%$ \\
\hline \multirow{2}{*}{$\begin{array}{l}\text { Hydrocelec- } \\
\text { tomy }\end{array}$} & $<50 \mathrm{k}$ & 0 & 0 & 0 & $14.3 \%$ & $14.3 \%$ & 0 & $71.4 \%$ \\
\hline & $50-200 K$ & $4.6 \%$ & $4.6 \%$ & $13.6 \%$ & $4.6 \%$ & $13.6 \%$ & $4.6 \%$ & $54.6 \%$ \\
\hline \multirow{2}{*}{$\begin{array}{l}\text { Cesarean } \\
\text { section }\end{array}$} & $<50 k$ & 0 & 0 & $60 \%$ & $20 \%$ & 0 & 0 & $20 \%$ \\
\hline & 50-200K & $12.5 \%$ & $12.5 \%$ & $50 \%$ & $12.5 \%$ & 0 & 0 & $12.5 \%$ \\
\hline \multirow[t]{2}{*}{ Tubal ligation } & $<50 k$ & 0 & 0 & $25 \%$ & $25 \%$ & 0 & 0 & $50 \%$ \\
\hline & 50-200K & $33 \%$ & 0 & $67 \%$ & 0 & 0 & 0 & 0 \\
\hline \multirow{2}{*}{$\begin{array}{l}\text { Ovarian } \\
\text { cystectomy }\end{array}$} & $<50 k$ & 0 & 0 & $25 \%$ & $25 \%$ & 0 & 0 & $50 \%$ \\
\hline & 50-200K & 0 & 0 & $20 \%$ & 0 & 0 & 0 & $80 \%$ \\
\hline \multirow[t]{2}{*}{ Varicose vein } & $<50 k$ & $16.7 \%$ & 0 & 0 & 0 & $16.7 \%$ & 0 & $66.7 \%$ \\
\hline & 50-200K & $12.5 \%$ & $6.3 \%$ & $18.8 \%$ & $6.3 \%$ & $12.5 \%$ & 0 & $43.8 \%$ \\
\hline \multirow[t]{2}{*}{ Vascular access } & $<50 k$ & 0 & 0 & $8.3 \%$ & $8.3 \%$ & $8.3 \%$ & 0 & $75 \%$ \\
\hline & 50-200K & $7.4 \%$ & 0 & $22.2 \%$ & $7.4 \%$ & 0 & $3.7 \%$ & $59.3 \%$ \\
\hline \multirow[t]{2}{*}{ Amputation } & $<50 k$ & 0 & 0 & $11.1 \%$ & $11.1 \%$ & 0 & 0 & $77.8 \%$ \\
\hline & 50-200K & $13.3 \%$ & $6.7 \%$ & $13.3 \%$ & $13.3 \%$ & $6.7 \%$ & $13.3 \%$ & $33.3 \%$ \\
\hline \multirow[t]{2}{*}{ Banding varices } & $<50 k$ & 0 & 0 & $27.3 \%$ & $9.1 \%$ & $36.4 \%$ & 0 & $27.3 \%$ \\
\hline & 50-200K & $3.7 \%$ & $3.7 \%$ & $33.3 \%$ & $3.7 \%$ & $18.5 \%$ & $3.7 \%$ & $33.3 \%$ \\
\hline \multirow[t]{2}{*}{ Eo dilations } & $<50 k$ & $7.1 \%$ & $7.1 \%$ & 0 & $7.1 \%$ & $28.4 \%$ & 0 & $50 \%$ \\
\hline & 50-200K & $3.1 \%$ & 0 & $15.6 \%$ & $6.3 \%$ & $18.8 \%$ & $3.1 \%$ & $53.1 \%$ \\
\hline \multirow[t]{2}{*}{ Peg tube } & $<50 k$ & 0 & 0 & 0 & $7.7 \%$ & $23.1 \%$ & 0 & $69.2 \%$ \\
\hline & 50-200K & $5.4 \%$ & $2.7 \%$ & $10.8 \%$ & $2.7 \%$ & $5.4 \%$ & $2.7 \%$ & $70.3 \%$ \\
\hline
\end{tabular}




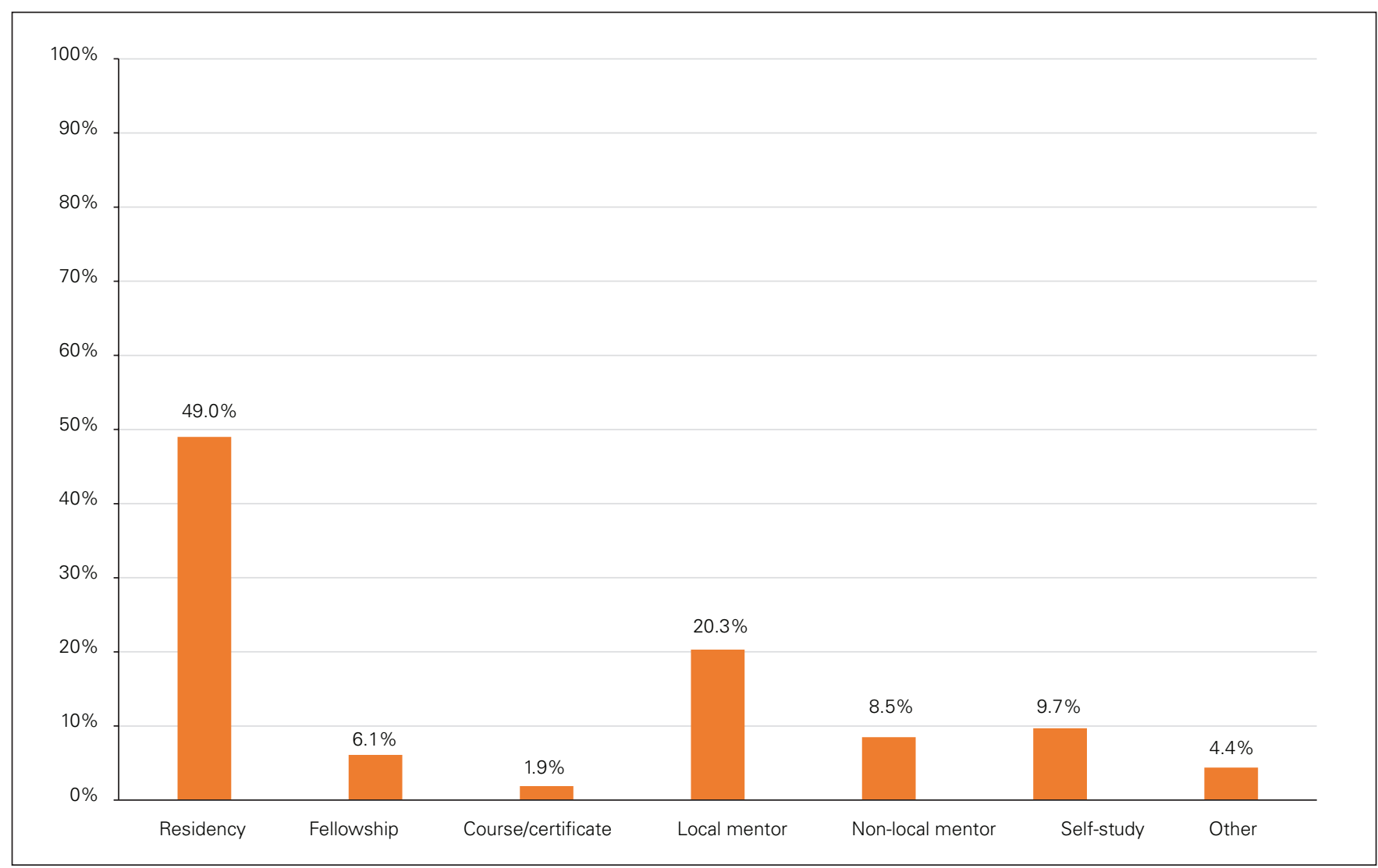

Fig. 1. Training for non-core procedures. Averaged responses for how surgeons achieved competence in the non-general surgery procedures identified as being performed significantly more frequently in small- and mid-size communities.

The UBC general surgery curriculum parallels largecentre general surgery practice and no longer includes rotations in plastic surgery, obstetrics and gynecology, urology, otolaryngology, neurosurgery, or vascular surgery. While residency was the source of competency for many respondents, it seems likely that future trainees will not be as prepared for a small or mid-sized community practice as their predecessors were. ${ }^{8}$ In fact, very few surgeons were confident that today's graduating residents are definitely prepared for a community practice $(3 \%)$, and half of the responding surgeons replied that they are probably or definitely not prepared (49\%).

While it is unreasonable to ask our general surgery residency programs to produce graduates fluent in multiple specialties, we feel the majority of the procedures identified here would be within the grasp of today's general surgery trainees. Going forward, we see several options that may better prepare general surgeons for a rural or community practice: establishing networks of peer mentors, training courses for rural/ community surgeons, webcast rounds for surgeons in populations of similar sizes, a rural/community stream within the Competence by Design (CBD) residency framework, proactive succession planning, and/or a 1-2 year rural surgery fellowship. Targeted courses and webcast rounds would provide an avenue for rural practitioners to stay in tune with current evidence. After residency, peer mentorship was the next most common avenue for achieving procedural competence. In $\mathrm{BC}$, an online network for general surgeons was established as part of the UBC strategic investment fund (UBC Reticulum) to promote and foster this type of mentorship. It allows surgeons in BC to identify and communicate and collaborate with surgeons willing to mentor specific procedures.

The CBD residency framework claims increased flexibility to focus on skills development, and we feel this could be tailored to better prepare those residents who will be pursuing a broad-spectrum community practice. ${ }^{9}$ When CBD was piloted in the University of Toronto's orthopedic surgery program, many residents successfully graduated a year early. ${ }^{10}$ If similar results are experienced in general surgery, there may be more flexibility to expand skill sets without extending training beyond the standard 5 years; residents could use the extra time to seek out rotations in other specialties to gain procedural competence. In an ideal scenario, rural or community hospitals would have a formalized succession planning process to identify upcoming needs and start the recruiting process while an 
applicant is still in training. In this manner, the trainee could identify specific needs of their future community and appropriately tailor their education.

The Future of General Surgery Task Force proposed a residency curricular change that could allow residents to tailor their education to practise in small communities. ${ }^{3}$ Some of the difficulty in trying to create a structured curriculum will be accounting for the uniqueness of the populations, geographic arrangements and available resources that lead to different needs and capabilities in each of these hospitals. This study will hopefully serve to inform curricular design to better prepare general surgery residents for practice in small and mid-sized communities.

In the setting where a new graduate will be taking over the practice of a retiring surgeon, another avenue for ensuring new graduates are prepared to provide the services required within their unique community is to transition into practice. The senior surgeon can train the young surgeon to competence in areas of deficit to ensure the community's needs are met. This can be a symbiotic relationship, as it allows the experienced surgeon to share the office, administrative, and call workload while not relinquishing their entire practice at once.

Our survey results may not be generalizable outside of BC. There is potential for bias, as surgeons who perform non-core procedures may have been more likely to respond. The large number of surveys that were not completed may in part be due to the length of the survey, and this likely contributed to a small sample size.

\section{Conclusion}

Only 3\% of British Columbia's general surgeons are confident that graduating residents are "definitely ready" for a broad-based rural or community practice. Surgeons in small or mid-sized communities in BC perform significantly more non-core procedures than surgeons at large centres. As general surgery residency training becomes increasingly focused, today's graduates are likely less prepared for these procedures than their predecessors were. Our survey results provide insight for residents interested in this type of practice and may contribute to the development of rural surgery curricula to ensure our communities' needs are being met with quality surgical care.
Affiliations: From the Division of General Surgery, University of British Columbia, Vancouver, BC.

Competing interests: Hamish Hwang is an associate editor of C7S; he was not involved in the review or decision to accept this paper for publication. No other competing interests were declared.

Contributors: All authors contributed substantially to the conception, writing and revision of this article and approved the final version for publication.

Content licence: This is an Open Access article distributed in accordance with the terms of the Creative Commons Attribution (CC BY-NC-ND 4.0) licence, which permits use, distribution and reproduction in any medium, provided that the original publication is properly cited, the use is noncommercial (i.e., research or educational use), and no modifications or adaptations are made. See: https://creativecommons.org/licenses/by-nc-nd/4.0/

Disclaimer: The views expressed in this article are those of the authors, and do not represent the views of the University of British Columbia nor the UBC general surgery residency program.

\section{References}

1. Pollett WG, Dicks E. Training of canadian general surgeons: Are they really prepared? CAGS questionnaire on surgical training. Can $\mathcal{F}$ Surg 2005;48:219-24.

2. Royal College of Physicians and Surgeons of Canada. Objectives of training in the specialty of general surgery; 2017 Available: www .royalcollege.ca/rcsite/documents/ibd/general-surgery-otr-e.pdf (accessed 2019 Aug. 11).

3. Webber EM, Ronson AR, Gorman LJ, et al. The future of general surgery: evolving to meet a changing practice. 7 Surg Educ 2016;73:496-503.

4. Statistics Canada. Population and dwelling count highlight tables, 2016 census. Available: https://www12.statcan.gc.ca/census -recensement/2016/dp-pd/hlt-fst/pd-pl/Table.cfm?Lang=Eng\&T $=703 \& \mathrm{~S}=87 \& \mathrm{O}=\mathrm{A}$ (accessed 2019 Aug. 16).

5. Warnock G, Miles P. Why canada needs networks to provide rural surgical care, including family doctors with essential surgical skills. Can 7 Surg 2015;58:367-8.

6. van der Geest, Lydia GM, van Rijssen LB, Molenaar IQ, et al. Volume-outcome relationships in pancreatoduodenectomy for cancer. HPB (Oxford) 2016;18:317-24.

7. Canadian Resident Matching Service. Program descriptions - first iteration. Availalbe: http://www.carms.ca/match/r-1-main-residency -match/program-descriptions (accessed 2019 Aug. 17).

8. UBC General Surgery Residency Program. Rotation matrix. Availalbe: https://gsresidency.surgery.med.ubc.ca/current-residents/rotations-sitespecific-info/rotation-matrix/ (accessed 2019 Aug. 17, 2019).

9. Royal College of Physicians and Surgeons of Canada. Competence by design: What you need to know 2017. Available: www .royalcollege.ca/rcsite/documents/cbd/cbd-residents-guide-e.pdf (accessed 2019 Aug. 9).

10. Nousiainen MT, Mironova P, Hynes M, et al. Eight-year outcomes of a competency-based residency training program in orthopedic surgery. Med Teach 2018;40:1042-54. 